\title{
Oral care and oral assessment guide in breast cancer patients receiving everolimus and exemestane: Subanalysis of a randomized controlled trial (Oral Care-BC)
}

Masahiro Umeda ( $\nabla$ mumeda@nagasaki-u.ac.jp )

Nagasaki University Graduate School of Biomedical Sciences

Yoshihide Ota

Department of Oral and Maxillofacial Surgery, Tokai University School of Medicine

Kosuke Kashiwabara

Department of Biostatics, School of Public Health, University of Tokyo

Naoki Hayashi

Department of Breast Surgical Oncology, St. Luke's International Hospital

Mariko Naito

Department of Oral Epidemiology, Graduate School of Biomedical and Health Sciences

Toshinari Yamashita

Department of Breast and Endocrine Surgery, Kanagawa Cancer Center

Hirofumi Mukai

Department of Breast and Medical Oncology, National Cancer Center Hospital East

\section{Katsuhiko Nakatsukasa}

Department of Breast and Endocrine Surgery, Kyoto Prefectural University of Medicine

\section{Takeshi Amemiya}

Department of Dentistry and Oral and Maxillofacial Surgery, Kyoto Prefectural University of Medicine

Ken-ichi Watanabe

Department of Breast Surgery, Hokkaido Cancer Center

Hironobu Hata

Department of Dentistry, Hokkaido Cancer Center

\section{Yuichiro Kikawa}

Department of Breast Surgery, Kobe City Medical Center General Hospital

Naoki Taniike

Department of Dentistry and Oral and Maxillofacial Surgery, Kobe City Medical Center General Hospital

Takashi Yamanaka

Department of Breast and Endocrine Surgery, Kanagawa Cancer Center

\section{Sachiyo Mitsunaga}

Department of Dentistry and Oral and Maxillofacial Surgery, Kanagawa Cancer Center 


\section{Kazuhiko Nakagami}

Department of Breast and Endocrine Surgery, Shizuoka General Hospital

\section{Moriyasu Adachi}

Department of Oral and maxillofacial Surgery, Shizuoka General Hospital

\section{Naoto Kondo}

Department of Breast and Endocrine Surgery, Nagoya City University Hospital

\section{Yasuyuki Shibuya}

Department of Oral and maxillofacial Surgery, Nagoya City University Graduate School of Medical

Sciences

\section{Naoki Niikura}

Department of Breast and Endocrine Surgery, Tokai University School of Medicine

\section{Research article}

Keywords: benzethonium, breast neoplasm, dexamethasone, everolimus, exemestane, mouthwash, mucositis, quality of life

Posted Date: May 5th, 2020

DOI: https://doi.org/10.21203/rs.3.rs-25215/v1

License: (a) This work is licensed under a Creative Commons Attribution 4.0 International License. Read Full License

Version of Record: A version of this preprint was published at Annals of Translational Medicine on April 1st, 2021. See the published version at https://doi.org/10.21037/atm-20-6488. 


\section{Abstract}

\section{Background}

This randomized, controlled, multicenter, open-label, phase III study was conducted to determine whether professional oral care (POC) reduces oral mucositis in estrogen receptor-positive metastatic breast cancer patients treated with everolimus and exemestane.

\section{Methods}

One hundred seventy-four patients were randomized into the POC group $(n=86)$ or the control group $(n=$ 88). Four patients in the POC group and one patient in the control group were excluded from the study because they did not receive the protocol treatment. Thus, 169 patients (POC group: 82 patients; control group: 87 patients) were evaluated for efficacy and safety. The POC group received oral health instruction $(\mathrm{OHI})$, professional mechanical tooth and tongue cleaning, gargling with a benzethonium chloride mouthwash, and dexamethasone ointment when grade 1 mucositis manifested. The control group received $\mathrm{OHI}$ and gargling. Eight weeks after everolimus and exemestane were administered, the patients were evaluated for oral status (based on the Oral Assessment Guide [OAG] criteria) and oral mucositis status (assessed with Common Terminology Criteria for Adverse Events [CTCAE] functional and clinical examinations).

Results

The incidences of oral mucositis of any grade and severe mucositis of grade 2 were significantly lower in the POC group ( $p=0.034$ and $p=0.013$, respectively), based on the CTCAE functional and CTCAE clinical examinations ( $p=0.034$ and $p<0.001$, respectively). The longitudinal data of the total OAG score $(p=$ $0.012)$, total OAG grade $(p=0.014)$, and the longitudinal data of the OAG score of teeth/dentures $(p=$ $0.026)$ and mucous membranes $(p=0.011)$ were significantly different between the two groups. The grade of oral mucositis diagnosed with CTCAE functional/clinical examinations was significantly correlated with the OAG grade for swallow $(p=0.04 / p<0.01)$, lip $(p=<0.01 / p<0.01)$, teeth/dentures $(p=$ $0.04 / p=0.01)$, mucous membrane $(p<0.01 / p<0.01)$, tongue $(p<0.01 / p<0.01)$, and saliva $(p<0.01 / p<$ $0.01)$.

\section{Conclusions}

Professional oral care may prevent oral mucositis and improve the condition of teeth/dentures in patients receiving everolimus and exemestane treatment.

Trial registration:

The study protocol was registered on the website of the University Hospital Medical Information Network (Tokyo, Japan; protocol ID 000016109) on January 5, 2015, and was registered on the ClinicalTrials.gov website (ClinicalTrials.gov identifier: NCT02376985) on March 3, 2015. 
\# These authors contributed equally to this work.

\section{Background}

Oral mucositis is a clinically significant adverse event of cancer therapy. Its incidence is $5-40 \%$ among patients receiving standard-dose chemotherapy, and $75 \%$ or greater among patients receiving high-dose chemotherapy with stem-cell transplantation or radiation therapy for head and neck cancer $[1,2]$. When the oral cavity and the salivary glands are exposed to radiation therapy, hyposalivation, oral mucositis, taste loss, trismus, radiation-induced dental caries, and osteoradionecrosis are the most common adverse events. Therefore, early and active participation of dental professionals may be paramount in patients' quality of life during and after radiotherapy [3]. Oral mucositis reduces the quality of life of patients and may result in the discontinuation of treatment and a poorer prognosis. Molecularly targeted therapeutic drugs can also cause oral mucositis. In particular, among patients receiving everolimus treatment, the incidence of oral mucositis of any grade is as high as $58 \%$ and is $81 \%$ among Asian patients and $91 \%$ among Japanese patients, based on subgroup analyses in the BOLERO-2 study [4,5]. These findings could be attributable to the fact that the recommended dose of everolimus (10 $\mathrm{mg})$ does not take into account weight and body mass index, and Asian individuals have a smaller body surface area. Among Asians, people in East Asia, including Japan, are more likely to have strong adverse effects because of their lower weight than are people in West Asia and South Asia. However, the mechanisms and prevention of everolimus-induced oral mucositis have not been elucidated.

Based on an evidence level of 3, the Mucositis Study Group of Multinational Association for Supportive Care in Cancer and the International Society of Oral Oncology (MASCC/ISOO) recommend oral care for all patients receiving cancer chemotherapy and radiotherapy [2], although no data from large-scaled randomized controlled trials support the efficacy of oral care in preventing oral mucositis. Therefore, we conducted a randomized controlled trial to determine whether professional oral care $(\mathrm{POC})$ - consisting of professional mechanical tooth cleaning, scaling, gargling with an antiseptic mouthwash containing benzethonium chloride, oral hygiene instruction, and use of dexamethasone ointment when grade 1 mucositis manifests-truly reduces oral mucositis in estrogen receptor-positive metastatic breast cancer patients treated with everolimus and exemestane (i.e., the Oral Care Evaluation to Prevent Oral Mucositis in Estrogen Receptor-Positive Metastatic Breast Cancer Patients Treated with Everolimus [Oral Care-BC] trial). This subanalysis study focused on the relationship between POC and changes in the Oral Assessment Guide (OAG) score/grade [6, 7].

\section{A summary of the study protocol and treatment in the Oral Care-BC trial}

Oral Care-BC is a Japan-based, phase 3, multicenter randomized clinical trial that assessed the effectiveness of POC in preventing oral mucositis in patients treated with everolimus and exemestane for hormone receptor-positive, human epidermal growth factor receptor type 2 (HER2)-negative metastatic 
breast cancer [8]. Patients were randomized into the POC group and the control group in a 1:1 ratio (stratified, based on the center, use of bone-modifying agents, patient's age, and history of receiving chemotherapy within 3 months). Patients in the POC group received oral hygiene instruction, professional mechanical tooth cleaning, scaling, gargling with antiseptic mouthwash containing benzethonium chloride (Neostelin Green 0.2\% mouthwash solution; Nihon Shika Yakuhin, Co., Ltd., Osaka, Japan), and dexamethasone ointment (Dexaltin Oral Ointment, 1 mg/g; Nihon Kayaku Co., Ltd, Tokyo Japan) when grade 1 mucositis manifested. The primary endpoint was the incidence of oral mucositis of any grade after everolimus and exemestane treatment, as evaluated with functional examination.

The inclusion criteria were as follows: women aged 20 years or older who were postmenopausal and had metastatic histologically or cytologically confirmed hormone receptor-positive, HER2-negative breast cancer; were newly prescribed everolimus $10 \mathrm{mg}$ and exemestane $25 \mathrm{mg}$; had an Eastern Cooperative Oncology Group performance status of $0-1$ [9]; and had adequate renal function (serum creatinine level $\leq 1.5 \times$ the upper limit of normal). The exclusion criteria consisted of (1) edentulism; (2) oral mucositis within 1 month; (3) chemotherapy administered within 1 month before randomization (except for bisphosphonate drugs or denosumab); and (4) severe or uncontrolled medical conditions.

\section{Methods}

\section{Patients}

Patients treated with everolimus and exemestane for hormone receptor-positive, human epidermal growth factor receptor type 2 (HER2)-negative metastatic breast cancer were recruited into the study. The inclusion and exclusion criteria were described previously. Between May 2015 and December 2017, 175 patients were screened in Japan. Of these, 174 eligible patients from 31 centers were enrolled in the Oral Care-BC trial (Fig. 1). Among the enrolled patients, 86 patients were allocated to the POC group and 88 patient were allocated to the control group. Four patients in the POC group and one in the control group were excluded from the study because they did not receive the protocol treatment. Thus, 169 patients (82 in the POC group and 87 in the control group) were evaluated for efficacy and safety. This study was conducted in accordance with the 2013 Declaration of Helsinki criteria [10]. The institutional review boards at each of the 31 study sites approved the study protocol. Written informed consent was obtained from all participants included in the study.

\section{Evaluation of intraoral findings}

Before the administration of everolimus and exemestane, a dentist examined the oral status of each patient once weekly for 8 weeks by using the OAG criteria, which were modified by Anderson et al. [6] from the original guideline described by Eilers [7]. The OAG is used to evaluate the oral condition, and is based on eight factors: swallow, lip, tongue, saliva, mucous membrane, gingivae, teeth/dentures, and voice. Each factor is categorized as grade 1 (normal), grade 2 (mild to moderate change), or grade 3 (moderate to severe change). Furthermore, the oral status is evaluated as "normal" when the total OAG 
score is $\leq 8$, as "mild functional disturbance" when the total OAG score is $9-12$, and as "moderate or severe functional disturbance" when the total OAG score is $\geq 13$.

The patients were examined once weekly for oral mucositis by an oncologist, who used the functional examination of Common Terminology Criteria for Adverse Events (CTCAE) guidelines, version 4.0 [11], and by a dentist, who conducted clinical examination in accordance with CTCAE guidelines, version 3.0 [12]. The functional examination findings were "grade 1" for asymptomatic or mild symptoms for which an intervention was not indicated; "grade 2" for moderate pain that did not interfere with oral intake but was an indication for a modified diet; and "grade 3" for severe pain that interfered with oral intake. The clinical examination findings were "grade 1" for erythema of the mucosa; "grade 2" for patchy ulcerations or pseudomembranes; and "grade 3" for confluent ulcerations or pseudomembranes, and bleeding with minor trauma. Before the administration of everolimus and exemestane, periodontal disease was further classified by a dentist into three categories: "mild" for a pocket depth of $\leq 3.0 \mathrm{~mm}$ and mobility of grade 1 or less; "moderate" for a pocket depth 4-6 mm or one or more teeth with grade 2 mobility; and "severe" for a pocket depth $\geq 7 \mathrm{~mm}$ or one or more teeth with grade 3 mobility.

\section{Outcome}

The primary endpoint was to examine whether a difference would exist between the POC group and the control group in the total score of the OAG. The secondary endpoints were (1) to examine whether a difference existed in each OAG score between the POC group and the control group and (2) to examine whether a relationship existed between oral mucositis and the total OAG score, or between oral mucositis and each OAG score.

\section{Statistical analysis}

The differences in the incidence of oral mucositis in the POC group and in the control group were analyzed by using the Fisher test. The differences in periodontal disease and the OAG score between the POC and control groups were analyzed by using the chi-square test or the Wilcoxon rank-sum test. The longitudinal data of changes in the OAG score between the POC group and the control group were analyzed by using the linear mixed effect model. A two-tailed $p$ value of $5 \%$ or less was significant.

\section{Ethics and registration}

The study was approved by Institutional Review Board for Clinical Research, Tokai University (approval no.: 14R-063). The study protocol was registered on the website of the University Hospital Medical Information Network (Tokyo, Japan; protocol ID 000016109) on January 5, 2015, and registered on the ClinicalTrials.gov website (ClinicalTrials.gov identifier: NCT02376985) on March 3, 2015. Details are available at the following addresses:

(1) https://upload.umin.ac . jp/cgi-open-bin/ctr/ctr.cgi?function = brows\&action = brows\&type = summary\&recptno $=$ R000018713\&language $=\mathrm{J}$

(2) https://clinicaltrials.gov/ct2/show/NCT02376985 


\section{Results}

\section{Main results of the Oral Care-BC trial}

Tables 1 and 2 show the patients' characteristics and main results of Oral Care-BC, as reported previously [11]. Based on functional examinations, the incidence of grade 1 oral mucositis was significantly different between the POC group (75.6\%) and the control group (89.7\%) $(p=0.034)$. The incidence of grade 2 (i.e., severe) oral mucositis was also significantly different between the POC group $(34.1 \%)$ and the control group (54.0\%) ( $p=0.013)$. Based on clinical examinations, grade 1 oral mucositis occurred in $80.5 \%$ of the POC group patients and in $93.1 \%$ of the control group patients $(p=0.034)$, and grade 2 oral mucositis occurred in $40.2 \%$ of the POC group patients and in $70.1 \%$ of the control group patients $(\mathrm{p}<$ $0.001)$. 
Table 1

Patient characteristics

\begin{tabular}{|c|c|c|c|}
\hline Characteristics & POC group $(n=82)$ & Control group $(n=87)$ & $p$-value \\
\hline Age & & & 0.57 \\
\hline mean (SD) & $63.7(7.4)$ & $62.9(8.9)$ & \\
\hline median (min, max) & $64.0(49,84)$ & $64.0(42,83)$ & \\
\hline Bone-modifying agent & & & 0.84 \\
\hline Not used & 39 & 40 & \\
\hline Used & 43 & 47 & \\
\hline Chemotherapy & & & 0.55 \\
\hline Not used & 74 & 76 & \\
\hline Used & 8 & 11 & \\
\hline PS & & & 0.14 \\
\hline 0 & 63 & 72 & \\
\hline 1 & 14 & 15 & \\
\hline 2 & 1 & 0 & \\
\hline 3 & 0 & 0 & \\
\hline 4 & 0 & 0 & \\
\hline Missing & 4 & 0 & \\
\hline $\mathrm{BMI}\left(\mathrm{kg} / \mathrm{m}^{2}\right)$ & & & 0.76 \\
\hline mean (SD) & $22.95(3.84)$ & $22.77(3.55)$ & \\
\hline median (min, max) & $22.52(14.9,35.9)$ & $22.85(16.4,34.2)$ & \\
\hline Smoking & & & 0.50 \\
\hline Nonsmoker & 75 & 83 & \\
\hline Smoker & 4 & 4 & \\
\hline Missing & 3 & 1 & \\
\hline Alcohol drinking & & & 0.90 \\
\hline Nondrinker & 64 & 69 & \\
\hline Drinker & 14 & 15 & \\
\hline Missing & 4 & 3 & \\
\hline
\end{tabular}


Table 2

Incidence probability of oral mucositis

\begin{tabular}{|c|c|c|c|}
\hline Oral mucositis & POC group $(n=82)$ & Control group $(n=87)$ & $p$-value \\
\hline $\begin{array}{l}\text { grade } 1 \text { or more } \\
\text { (by functional examination) }\end{array}$ & & & 0.034 \\
\hline Yes & 62 & 78 & \\
\hline No & 20 & 9 & \\
\hline \multicolumn{4}{|l|}{$\begin{array}{l}\text { grade } 1 \text { or more } \\
\text { (by clinical examination) }\end{array}$} \\
\hline Yes & 66 & 81 & 0.034 \\
\hline No & 16 & 6 & \\
\hline \multicolumn{4}{|l|}{$\begin{array}{l}\text { grade } 2 \text { or more } \\
\text { (by functional examination) }\end{array}$} \\
\hline Yes & 28 & 47 & 0.013 \\
\hline No & 54 & 40 & \\
\hline \multicolumn{4}{|l|}{$\begin{array}{l}\text { grade } 2 \text { or more } \\
\text { (by clinical examination) }\end{array}$} \\
\hline Yes & 33 & 61 & $<0.001$ \\
\hline No & 49 & 26 & \\
\hline
\end{tabular}

Table 3 shows the baseline OAG score and grade, and periodontal disease status in the POC and control groups. Before the administration of everolimus and exemestane, the POC group patients had significantly more severe periodontal disease than did the control group patients. The total OAG score, the $O A G$ grade, and the OAG score of teeth/dentures were also worse in the POC group than in the control group. 
Table 3

Background factors of baseline

\begin{tabular}{|c|c|c|c|c|c|}
\hline & \multicolumn{2}{|c|}{ POC group $(n=82)$} & \multicolumn{2}{|c|}{ Control group $(n=87)$} & $\begin{array}{l}p \text {-value } \\
<0.01 *\end{array}$ \\
\hline none & 18 & $22.0(13 ., 7-32.8)$ & 36 & $41.4(30.9-52.4)$ & \\
\hline mild & 63 & $76.8(67.2-86.3)$ & 51 & $58.6(47.6-69.1)$ & \\
\hline moderate & 0 & $0.0(0-4.5)$ & 0 & $0.0(0-4.2)$ & \\
\hline severe & 0 & $0.0(0-4.5)$ & 0 & $0.0(0-4.2)$ & \\
\hline OAG (total score) & & & & & $<0.01+$ \\
\hline $\mathrm{n}$, mean (SD) & 80 & $9.4(1.6)$ & 87 & $8.9(1.4)$ & \\
\hline median (min, max) & & $9.0(8,14)$ & & $8.0(8,15)$ & \\
\hline OAG (grade) & & & & & 0.01 * \\
\hline normal & 30 & $36.6(26.9-49.0)$ & 52 & $59.8(48.7-70.1)$ & \\
\hline mild & 45 & $54.9(44.7-67.3)$ & 33 & $37.9(27.7-49.0)$ & \\
\hline moderate / severe & 5 & $6.1(2.1-14.0)$ & 2 & $2.3(0.3-8.1)$ & \\
\hline Voice, n, \%, (95\% Cl) & & & & & 0.33 * \\
\hline grade 1 & 81 & $98.8(95.5-100)$ & 86 & $98.9(93.8-100)$ & \\
\hline grade 2 & 0 & $0.0(0-4.5)$ & 1 & $1.1(0-6.2)$ & \\
\hline grade 3 & 0 & $0.0(0-4.5)$ & 0 & $0.0(0-4.2)$ & \\
\hline Swallowing, n, \%, (95\% Cl) & & & & & $\nabla *$ \\
\hline grade 1 & 81 & $98.8(95.5-100)$ & 87 & $100.0(95.8-100)$ & \\
\hline grade 2 & 0 & $0.0(0-4.5)$ & 0 & $0.0(0-4.2)$ & \\
\hline grade 3 & 0 & $0.0(0-4.5)$ & 0 & $0.0(0-4.2)$ & \\
\hline Lip, n, \%, (95\% Cl) & & & & & 0.61 * \\
\hline grade 1 & 76 & $92.7(87.7-98.6)$ & 81 & $93.1(85.6-97.4)$ & \\
\hline grade 2 & 4 & $4.9(1.4-12.3)$ & 6 & $6.9(2.6-14.4)$ & \\
\hline grade 3 & 0 & $0.0(0-4.5)$ & 0 & $0.0(0-4.2)$ & \\
\hline Tooth, denture, n, \%, (95\% Cl) & & & & & $<0.01$ * \\
\hline grade 1 & 41 & $50.0(39.3-61.9)$ & 63 & $72.4(61.8-81.5)$ & \\
\hline grade 2 & 30 & $36.6(26.6-48.5)$ & 22 & $25.3(16.6-35.7)$ & \\
\hline & & Page 10/24 & & & \\
\hline
\end{tabular}




\begin{tabular}{|c|c|c|c|c|c|}
\hline grade 3 & 10 & $12.2(6.1-21.5)$ & 2 & $2.3(0.3-8.1)$ & \\
\hline Mucosa, n, \%, (95\% Cl) & & & & & 0.57 * \\
\hline grade 1 & 73 & $89.0(81.5-95.6)$ & 82 & $94.3(87.1-98.1)$ & \\
\hline grade 2 & 7 & $8.5(3.5-17)$ & 4 & $4.6(1.3-11.4)$ & \\
\hline grade 3 & 1 & $1.2(0-6.7)$ & 1 & $1.1(0-6.2)$ & \\
\hline Gingiva, n, \%, (95\% Cl) & & & & & 0.26 * \\
\hline grade 1 & 48 & $58.5(47.8-70.1)$ & 62 & $71.3(60.6-80.5)$ & \\
\hline grade 2 & 32 & $39.0(28.8-51)$ & 24 & $27.6(18.5-38.2)$ & \\
\hline grade 3 & 1 & $1.2(0-6.7)$ & 1 & $1.1(0-6.2)$ & \\
\hline Tongue, $\mathrm{n}, \%,(95 \% \mathrm{Cl})$ & & & & & 0.30 * \\
\hline grade 1 & 74 & $90.2(83-96.5)$ & 84 & $93.1(85.6-97.4)$ & \\
\hline grade 2 & 6 & $7.3(2.8-15.4)$ & 3 & $3.4(0.7-9.7)$ & \\
\hline grade 3 & 1 & $1.2(0-6.7)$ & 0 & $0.0(0-4.2)$ & \\
\hline Xerostomia, n, \%, (95\% Cl) & & & & & 0.15 * \\
\hline grade 1 & 70 & $85.4(77-93)$ & 81 & $93.1(85.6-97.4)$ & \\
\hline grade 2 & 11 & $13.4(7-23)$ & 6 & $6.9(2.6-14.4)$ & \\
\hline grade 3 & 0 & $0.0(0-4.5)$ & 0 & $0.0(0-4.2)$ & \\
\hline \multicolumn{6}{|l|}{ † wilcoxon rank sum test } \\
\hline * chi-square test & & & & & \\
\hline
\end{tabular}

\section{Change in the OAG score in the POC and control groups}

Total OAG score and grade in the control group increased in the first 2 weeks, whereas the total OAG score and grade in the POC group remained stable or decreased slightly during the whole study period. The longitudinal data of the total OAG score and total OAG grade were significantly different between the two groups (Fig. 2). An examination of each OAG score revealed significant differences between the POC and control groups in the longitudinal data of teeth/dentures and mucous membranes (Fig. 3).

\section{Relationship between the OAG score and oral mucositis}

The relationship between the total OAG score/grade and oral mucositis, based on clinical and functional examinations, is presented in Table 4. A significant correlation existed in that the total OAG score and grade increased as oral mucositis became more severe. With regard to the relationship between each 
OAG grade and mucositis, the OAG grades for swallow, lip, teeth/dentures, mucous membranes, tongue, and saliva were significantly associated with the severity of oral mucositis (Table 5). 
Table 4

Relationship between OAG total score/grade and oral mucositis

\begin{tabular}{|c|c|c|c|c|c|c|c|c|c|c|c|c|}
\hline \multirow[t]{2}{*}{ OAG } & \multicolumn{5}{|c|}{$\begin{array}{l}\text { Grade of oral mucositis (by } \\
\text { oncologist) }\end{array}$} & \multirow[t]{2}{*}{$\begin{array}{l}p- \\
\text { value }\end{array}$} & \multicolumn{5}{|c|}{$\begin{array}{l}\text { Grade of oral mucositis (by } \\
\text { dentist) }\end{array}$} & \multirow[t]{2}{*}{$\begin{array}{l}p \text { - } \\
\text { value }\end{array}$} \\
\hline & 0 & 1 & 2 & 3 & 4 & & 0 & 1 & 2 & 3 & 4 & \\
\hline Total score & & & & & & $<0.01$ & & & & & & $<0.01$ \\
\hline 3 & 0 & 0 & 0 & 0 & 0 & & 0 & 0 & 0 & 0 & 0 & \\
\hline 4 & 0 & 0 & 0 & 0 & 0 & & 0 & 0 & 0 & 0 & 0 & \\
\hline 5 & 0 & 0 & 0 & 0 & 0 & & 0 & 0 & 0 & 0 & 0 & \\
\hline 6 & 0 & 0 & 0 & 0 & 0 & & 0 & 0 & 0 & 0 & 0 & \\
\hline 7 & 0 & 0 & 0 & 0 & 0 & & 0 & 0 & 0 & 0 & 0 & \\
\hline 8 & 317 & 111 & 27 & 0 & 0 & & 494 & 110 & 34 & 1 & 0 & \\
\hline 9 & 195 & 97 & 28 & 4 & 0 & & 260 & 94 & 45 & 0 & 0 & \\
\hline 10 & 80 & 91 & 22 & 2 & 0 & & 119 & 60 & 59 & 0 & 0 & \\
\hline 11 & 43 & 42 & 13 & 1 & 0 & & 65 & 36 & 28 & 1 & 0 & \\
\hline 12 & 22 & 37 & 13 & 2 & 0 & & 38 & 25 & 21 & 4 & 0 & \\
\hline 13 & 12 & 17 & 13 & 1 & 0 & & 17 & 16 & 15 & 1 & 0 & \\
\hline 14 & 2 & 11 & 3 & 2 & 0 & & 6 & 9 & 8 & 0 & 0 & \\
\hline 15 & 0 & 2 & 0 & 2 & 0 & & 2 & 1 & 2 & 1 & 0 & \\
\hline 16 & 0 & 1 & 2 & 2 & 0 & & 0 & 1 & 4 & 0 & 0 & \\
\hline 17 & 1 & 0 & 0 & 0 & 0 & & 0 & 0 & 1 & 0 & 0 & \\
\hline 18 & 0 & 0 & 0 & 0 & 0 & & 0 & 0 & 0 & 0 & 0 & \\
\hline 19 & 0 & 0 & 1 & 0 & 0 & & 0 & 0 & 1 & 0 & 0 & \\
\hline 20 & 0 & 0 & 0 & 0 & 0 & & 0 & 0 & 0 & 0 & 0 & \\
\hline 21 & 0 & 0 & 0 & 0 & 0 & & 0 & 0 & 0 & 0 & 0 & \\
\hline 22 & 0 & 0 & 0 & 0 & 0 & & 0 & 0 & 0 & 0 & 0 & \\
\hline 23 & 0 & 0 & 0 & 0 & 0 & & 0 & 0 & 0 & 0 & 0 & \\
\hline 24 & 0 & 0 & 0 & 0 & 0 & & 0 & 0 & 0 & 0 & 0 & \\
\hline Total grade & & & & & & $<0.01$ & & & & & & $<0.01$ \\
\hline normal & 317 & 111 & 27 & 0 & 0 & & 494 & 110 & 34 & 1 & 0 & \\
\hline
\end{tabular}




\begin{tabular}{|lllllllllll|} 
mild & 340 & 267 & 76 & 9 & 0 & 482 & 215 & 153 & 5 & 0 \\
$\begin{array}{l}\text { moderate / } \\
\text { severe }\end{array}$ & 15 & 31 & 19 & 7 & 0 & 25 & 27 & 31 & 2 & 0 \\
\hline
\end{tabular}


Table 5

Relationship between each OAG grade and oral mucositis

\begin{tabular}{|c|c|c|c|c|c|c|c|c|c|c|c|c|}
\hline \multirow[t]{2}{*}{ OAG } & \multicolumn{5}{|c|}{$\begin{array}{l}\text { Grade of oral mucositis (by } \\
\text { oncologist) }\end{array}$} & \multirow[t]{2}{*}{$p-$} & \multicolumn{5}{|c|}{$\begin{array}{l}\text { Grade of oral mucositis (by } \\
\text { dentist) }\end{array}$} & \multirow[t]{2}{*}{$\begin{array}{l}p- \\
\text { value }\end{array}$} \\
\hline & 0 & 1 & 2 & 3 & 4 & & 0 & 1 & 2 & 3 & 4 & \\
\hline Voice & & & & & & 0.64 & & & & & & 0.89 \\
\hline grade 1 & 645 & 391 & 116 & 11 & 0 & & 973 & 341 & 205 & 5 & 0 & \\
\hline grade 2 & 29 & 17 & 5 & 4 & 0 & & 31 & 11 & 13 & 2 & 0 & \\
\hline grade 3 & 0 & 0 & 0 & 0 & 0 & & 0 & 0 & 0 & 0 & 0 & \\
\hline Swallow & & & & & & 0.04 & & & & & & $<0.01$ \\
\hline grade 1 & 658 & 390 & 105 & 8 & 0 & & 991 & 334 & 194 & 4 & 0 & \\
\hline grade 2 & 18 & 21 & 18 & 8 & 0 & & 16 & 19 & 26 & 4 & 0 & \\
\hline grade 3 & 0 & 0 & 0 & 0 & 0 & & 0 & 0 & 0 & 0 & 0 & \\
\hline Lips & & & & & & $<0.01$ & & & & & & $<0.01$ \\
\hline grade 1 & 556 & 291 & 78 & 7 & 0 & & 883 & 246 & 137 & 3 & 0 & \\
\hline grade 2 & 117 & 101 & 37 & 7 & 0 & & 120 & 103 & 59 & 4 & 0 & \\
\hline grade 3 & 0 & 0 & 0 & 0 & 0 & & 0 & 0 & 0 & 0 & 0 & \\
\hline Teeth/dentures & & & & & & 0.04 & & & & & & 0.01 \\
\hline grade 1 & 550 & 309 & 84 & 8 & 0 & & 739 & 277 & 164 & 5 & 0 & \\
\hline grade 2 & 120 & 101 & 38 & 8 & 0 & & 240 & 75 & 54 & 3 & 0 & \\
\hline grade 3 & 0 & 0 & 0 & 0 & 0 & & 0 & 0 & 0 & 0 & 0 & \\
\hline $\begin{array}{l}\text { Mucous } \\
\text { membrane }\end{array}$ & & & & & & $<0.01$ & & & & & & $<0.01$ \\
\hline grade 1 & 600 & 286 & 89 & 9 & 0 & & 937 & 243 & 133 & 5 & 0 & \\
\hline grade 2 & 71 & 104 & 23 & 6 & 0 & & 66 & 97 & 64 & 3 & 0 & \\
\hline grade 3 & 0 & 0 & 0 & 0 & 0 & & 0 & 0 & 0 & 0 & 0 & \\
\hline Gingivae & & & & & & 0.21 & & & & & & 0.08 \\
\hline grade 1 & 542 & 316 & 84 & 10 & 0 & & 760 & 281 & 154 & 5 & 0 & \\
\hline grade 2 & 133 & 94 & 38 & 6 & 0 & & 244 & 71 & 65 & 3 & 0 & \\
\hline grade 3 & 0 & 0 & 0 & 0 & 0 & & 0 & 0 & 0 & 0 & 0 & \\
\hline Tongue & & & & & & $<0.01$ & & & & & & $<0.01$ \\
\hline
\end{tabular}




\begin{tabular}{|c|c|c|c|c|c|c|c|c|c|c|c|c|}
\hline & grade 1 & 617 & 302 & 84 & 7 & 0 & & 936 & 269 & 142 & 2 & 0 \\
\hline & grade 2 & 59 & 92 & 25 & 8 & 0 & & 70 & 73 & 56 & 5 & 0 \\
\hline & grade 3 & 0 & 0 & 0 & 0 & 0 & & 0 & 0 & 0 & 0 & 0 \\
\hline Saliva & & & & & & & $<0.01$ & & & & & $<0.01$ \\
\hline & grade 1 & 592 & 334 & 105 & 8 & 0 & & 890 & 293 & 178 & 7 & 0 \\
\hline & grade 2 & 84 & 74 & 17 & 7 & 0 & & 118 & 57 & 40 & 1 & 0 \\
\hline & grade 3 & 0 & 0 & 0 & 0 & 0 & & 0 & 0 & 0 & 0 & 0 \\
\hline
\end{tabular}

\section{Discussion}

In this randomized controlled trial, we examined whether POC would truly reduce oral mucositis in estrogen receptor-positive metastatic breast cancer patients treated with everolimus and exemestane. We found that the incidences of oral mucositis of any grade and severe mucositis of grade 2 were significantly lower in patients in the POC group than in the control group, and the grade of oral mucositis was significantly correlated with OAG grade for swallow, lip, teeth/dentures, mucous membranes, tongue, and saliva. In this study, the functional examination classification of oral mucositis was determined by an oncologist, and the clinical examination classification was determined by a dentist familiar with findings in the oral cavity. Similar results were obtained by using any of the determination methods.

For patients with advanced breast cancer, the treatment aims are to delay disease progression while minimizing treatment-related adverse events. Oral mucositis associated with mammalian target of rapamycin (mTOR) inhibitor drug use reduces the oral food intake, drug adherence, and quality of life of patients [13]. On account of the clinical benefits and potential long-term use of everolimus and exemestane, establishing an effective strategy is desirable to prevent and reduce oral mucositis associated with these drugs.

Rugo et al. [14] reported that the prophylactic use of dexamethasone mouthwash reduced the incidence of severe oral mucositis in women with hormone receptor-positive, HER2-negative metastatic breast cancer (i.e., the SWISH trial). However, their study was a single-arm, phase 2 trial with a historical control.

To the best of our knowledge, the Oral Care-BC trial is the first randomized controlled trial that has clarified the efficacy of POC in preventing chemotherapy-related oral mucositis. Furthermore, the use of mouthwash containing steroids has not been allowed in Japanese insurance practice, and only dexamethasone- or triamcinolone-containing ointment has been approved for use on the oral mucosa.

Several assessment methods of the oral cavity have been used during chemotherapy or radiotherapy. Among these methods, Eilers OAG [7] is the most relevant method used in daily clinical practice [15]. The revised OAG is a revision of Eilers' OAG that can be applied to young people and to the elderly [7]. The relationship between the use of everolimus and exemestane and the change in the OAG score/grade has 
not been reported. Our study revealed that the OAG score was increased in the control group, whereas it was not increased in the POC group, and that the OAG score was increased because of an increase in the scores for mucous membranes and for teeth/dentures. However, other scores for voice, swallow, lip, gingivae, tongue, and saliva were not increased in either group.

With regard to the relationship between oral mucositis and the OAG score, the severity of mucositis was associated with the total OAG score and with the score of mucous membranes and swallow, lip, tongue, and saliva. These findings suggested that POC can prevent oral mucositis and improve the condition of teeth/dentures in patients receiving everolimus and exemestane treatment, and that preventing severe oral mucositis may improve swallow, lip, tongue, and saliva scores, although no significant difference existed in the current study.

This study has some limitations. First, our study was an open-label study with a small number of patients. Thus, the possibility of bias in the assessments cannot be denied. Second, the control group consisted of patients who did not receive POC and who were not intended for being treated with a steroid mouthwash, which is standard in some countries, because steroid mouthwash products are not available in Japan. Third, detailed data on oral hygiene and periodontal disease in both groups were not investigated in this study. Therefore, the mechanism by which POC suppresses the incidence of mucositis or the increase in the OAG score was not possible to elucidate.

\section{Conclusions}

The Oral Care-BC trial showed that POC is effective in suppressing oral mucositis in breast cancer patients receiving everolims and exemestane therapy [16]. Oral care is a method that can be easily administered globally and should be considered a new standard before administering these drugs, especially in the first 8 weeks of treatment. Furthermore, POC may also be helpful in reducing oral mucositis when using everolimus for other diseases such as renal cell carcinoma, subependymal giant cell astrocytoma associated with tuberous sclerosis complex, and advanced neuroendocrine tumors.

\section{Abbreviations}

CTCAE, Common Terminology Criteria for Adverse Events; OAG, Oral Assessment Guide; POC, professional oral care

\section{Declarations}

\section{Ethics approval and consent to participate:}

The study was approved by Institutional Review Board for Clinical Research, Tokai University (approval no.: 14R-063). In addition, the institutional review boards at each of the 31 study sites approved the study protocol. Written informed consent was obtained from all participants included in the study. 


\section{Consent for publication}

Not applicable.

\section{Availability of data and materials}

The datasets generated during the current study are available from the corresponding author on reasonable request.

\section{Competing interests:}

NN has received research funding to Tokai University (Tokyo, Japan) from Novartis (Basel, Switzerland), Bristol-Myers Squibb (New York, NY, USA), Chugai Pharmaceutical Co. (Tokyo, Japan), Nihon MediPhysics Co. Ltd. MSD (Tokyo, Japan), and Daiichi-Sankyo (Tokyo, Japan), and has received honoraria, consultancy, and speaker fees from AstraZeneca (Cambridge, United Kingdom), Novartis, Eisai (Tokyo, Japan), and Pfizer (New York, NY, USA) outside of the submitted work. T.Yamashita has received research grants and honoraria from Novartis, AstraZeneca, Eisai, Chugai, Taiho, Kyowa Kirin Pfizer, and Eli Lilly (Indianapolis, IN, USA). T.Yamanaka has received lecture fees from Novartis, Eisai, Chugai, Taiho (Tokyo, Japan), and Pfizer. NH has received personal fees from Chugai-pharma, Novartis, AstraZeneca, Pfizer, Kirin Pharma (Tokyo, Japan), Genomic Health, Inc. (Redwood City, CA, USA), Devicor Japan (Tokyo, Japan), and Allergan Japan (Tokyo, Japan) outside of the submitted work. HM received a grant from the Japanese government; honoraria from AstraZeneca, Pfizer, and Taiho; and grants from Daiichi Sankyo, Eisai, Nippon Kayaku (Tokyo, Japan), and Pfizer outside of the submitted work. The other authors declare no competing interests.

\section{Funding:}

This study was funded by Comprehensive Support Project for Oncology Research (CSPOR) of the Public Health Research Foundation. The research fund was provided to CSPOR by Novartis Pharma K. K. (Tokyo, Japan). Novartis Pharma K. K. took no part in this study, other than providing information relevant to the proper use of the study drug. All decisions concerning the planning, implementation, and publication of this study were made by the steering committee.

\section{Authors' contributions:}

All authors contributed to the study conception and design. Materials were prepared by T.Yamashita, T.Yamanaka, and K.Nakatsukasa. Data were collected by SM, HM, TA, HH, NT, MA, KW, YK, K.Nakagami, $\mathrm{NK}$, and YS. Analyses were conducted by KK, MN, and NH. The first draft of the manuscript was written by 
$\mathrm{MU}, \mathrm{YO}$, and NN, and all authors commented on previous versions of the manuscript. All authors have read and approved the final manuscript.

\section{Acknowledgements:}

We greatly appreciate all women who participated in this trial. We also thank all investigators and their collaborators who were dedicated to this study. We thank Editage (www.editage.jp) for their Englishlanguage editing services.

\section{References}

1. Sonis ST, Elting LS, Keefe D, Peterson DE, Schubert M, Hauer-Jensen M, et al. Perspectives on cancer therapy-induced mucosal injury: pathogenesis, measurement, epidemiology, and consequences for patients. Cancer. 2004;100:1995-2025.

2. Lalla RV, Bowen J, Barasch A, Elting L, Epstein J, Keefe DM, et al. MASCC/ISOO clinical practice guidelines for the management of mucositis secondary to cancer therapy. Cancer. 2014;120:145361.

3. Kielbassa AM, Hinkelbein W, Hellwig E, Meyer-Lückel H. Radiation-related damage to dentition. Lancet Oncol. 2006;7:326-35.

4. Noguchi S, Masuda N, Iwata H, Mukai $H$, Horiguchi J, Puttawibul P, et al. Efficacy of everolimus with exemestane versus exemestane alone in Asian patients with HER2-negative, hormone-receptorpositive breast cancer in BOLERO-2. Breast Cancer. 2014;21:703-14.

5. Ito Y, Masuda N, Iwata H, Mukai H, Horiguchi J, Tokuda Y, et al. Everolimus plus exemestane in postmenopausal patients with estrogen-receptor-positive advanced breast cancer-Japanese subgroup analysis of BOLERO-2. Gan To Kagaku Ryoho [Cancer and Chemotherapy]. 2015;42:6775. In Japanese.

6. Andersson P, Hallberg IR, Renvert S. Inter-rater reliability of an oral assessment guide for elderly patients residing in a rehabilitation ward. Spec Care Dentist. 2002;22:181-6.

7. Eilers J, Berger AM, Petersen MC. Development, testing, and application of the oral assessment guide. Oncol Nurs Forum. 1988;15:325-30.

8. Niikura N, Ota Y, Hayashi N, Naito M, Kashiwabara K, Watanabe Kl, et al. Evaluation of oral care to prevent oral mucositis in estrogen receptor-positive metastatic breast cancer patients treated with everolimus (Oral Care-BC): randomized controlled phase III trial. Jpn J Clin Oncol. 2016;46:879-82.

9. ECOG-ACRIN Cancer Research Group. ECOG performance status. 2019. https://ecogacrin.org/resources/ecog-performance-status Accessed 20 April 2019.

10. World Medical Association. World Medical Association Declaration of Helsinki: Ethical principles for medical research involving human subjects. JAMA. 2013;310:2191-4. 
11. National Cancer Institute. Common Terminology Criteria for Adverse Events (CTCAE) version 4.0. 2009.https://evs.nci.nih.gov/ftp1/CTCAE/CTCAE_4.03/CTCAE_4.03_2010-06-

14_QuickReference_5x7.pdf. Accessed 20 April 2020.

12. National Cancer Institute. Common Terminology Criteria for Adverse Events v3.0 (CTCAE). 2006. https://ctep.cancer.gov/protocolDevelopment/electronic_applications/docs/ctcaev3.pdf. Accessed 20 April 2020.

13. Rugo HS, Hortobagyi GN, Yao J, Pavel M, Ravaud A, Franz D, et al. Meta-analysis of stomatitis in clinical studies of everolimus: incidence and relationship with efficacy. Ann Oncol. 2016;27:519-25.

14. Rugo HS, Seneviratne L, Beck JT, Glaspy JA, Peguero JA, Pluard TJ, et al. Prevention of everolimusrelated stomatitis in women with hormone receptor-positive, HER2-negative metastatic breast cancer using dexamethasone mouthwash (SWISH): a single-arm, phase 2 trial. Lancet Oncol. 2017;18:65462.

15. Glenny AM, Gibson F, Auld E, Coulson S, Clarkson JE, Craig JV, et al. The development of evidencebased guidelines on mouth care for children, teenagers and young adults treated for cancer. Eur $\mathrm{J}$ Cancer. 2010;46:1399-412.

16. Niikura N, Nakatukasa K, Amemiya T, Watanabe KI, Hata H, Kikawa Y, et al. Oral care evaluation to prevent oral mucositis in estrogen receptor-positive metastatic breast cancer patients treated with everolimus (Oral Care-BC): a randomized controlled phase III trial. Oncologist. 2020;25:e223. doi:10.1634/theoncologist.2019-0382.

\section{Figures}




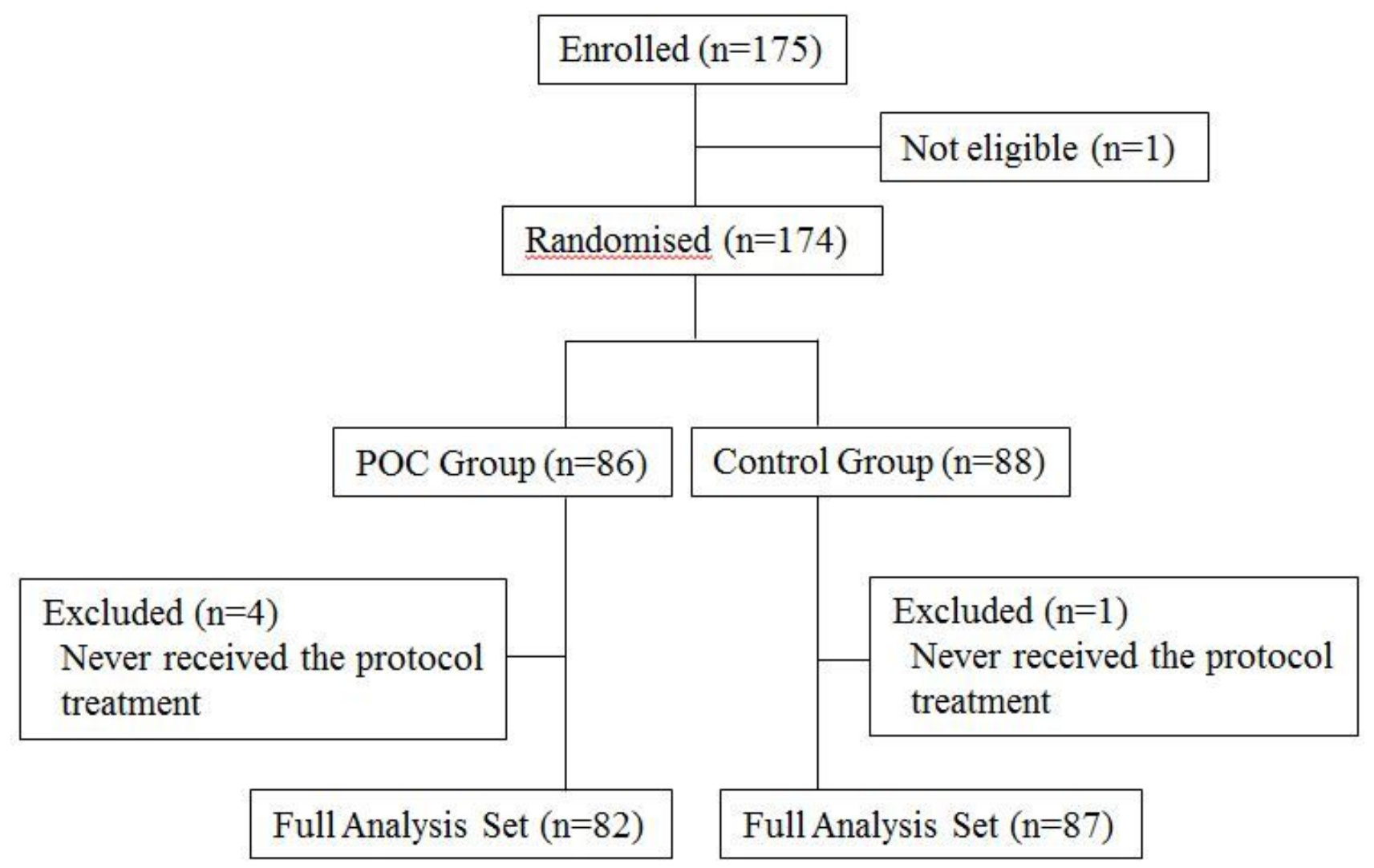

Figure 1

The CONSORT diagram POC, professional oral care; FAS, full analysis set; CONSORT, Consolidated Standards of Reporting Trials 


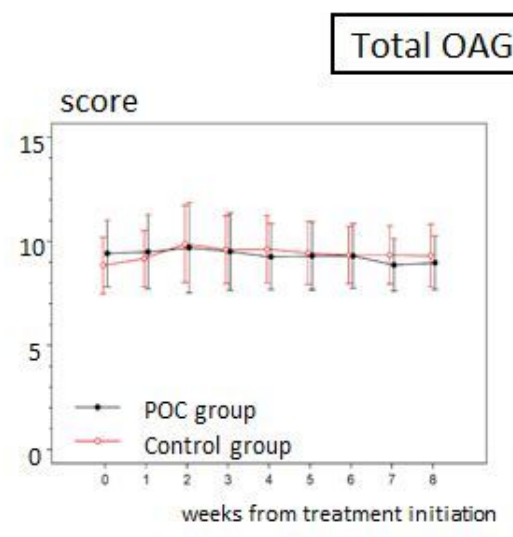

\section{(score)}

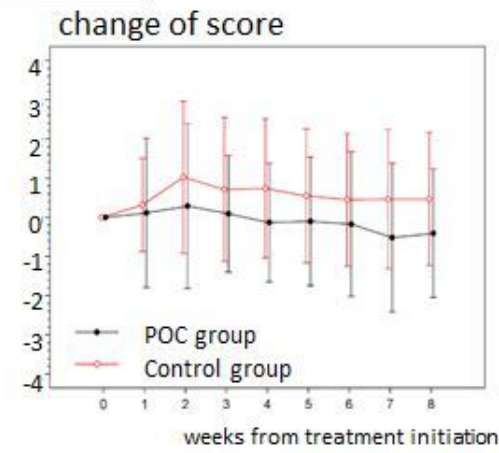

\begin{tabular}{lccc} 
OAG (score) & & & \\
\hline & $\begin{array}{c}\text { estimate } \\
\text { value }\end{array}$ & $\begin{array}{c}\text { confidence } \\
\text { interval }\end{array}$ & $p$-value \\
\hline point & 1.14 & $(0.95,1.34)$ & $<0.001$ \\
point $\times$ baseline & -0.12 & $(-0.14,-0.09)$ & $<0.001$ \\
point $\times$ intervention & -0.08 & $(-0.15,-0.02)$ & 0.012 \\
\hline
\end{tabular}

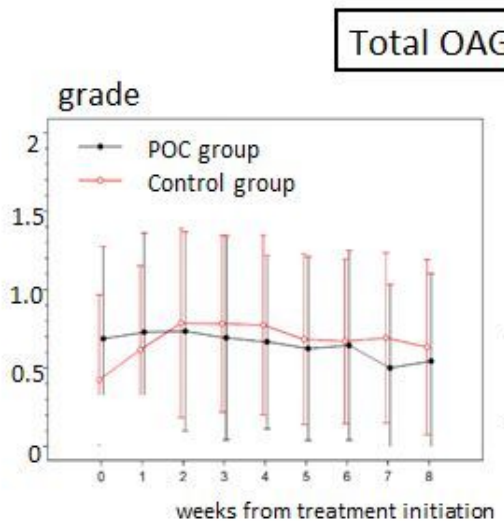

\section{(grade)}

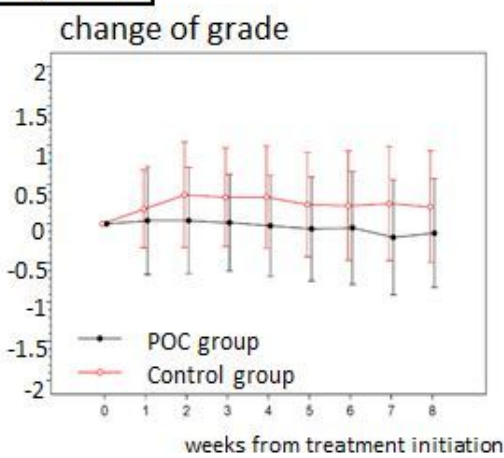

OAG (grade)

\begin{tabular}{lccc}
\hline & $\begin{array}{c}\text { estimate } \\
\text { value }\end{array}$ & $\begin{array}{c}\text { confidence } \\
\text { interval }\end{array}$ & $p$-value \\
\hline point & 0.11 & $(0.09,0.12)$ & $<0.001$ \\
point $\times$ baseline & -0.13 & $(-0.15,-0.11)$ & $<0.001$ \\
point $\times$ intervention & -0.03 & $(-0.05,-0.01)$ & 0.014 \\
\hline
\end{tabular}

\section{Figure 2}

Longitudinal data of the total OAG score/grade in the POC group and the control group OAG, Oral Assessment Guide; POC, professional oral care 

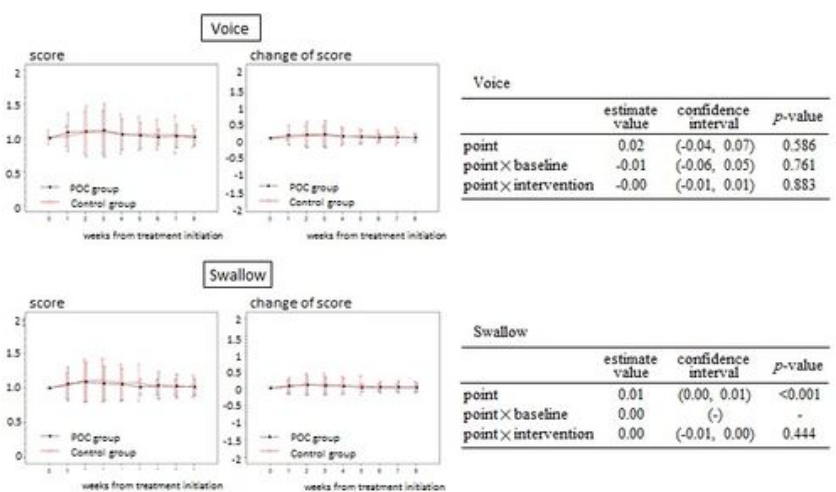

Lip

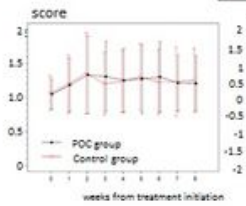

change of score
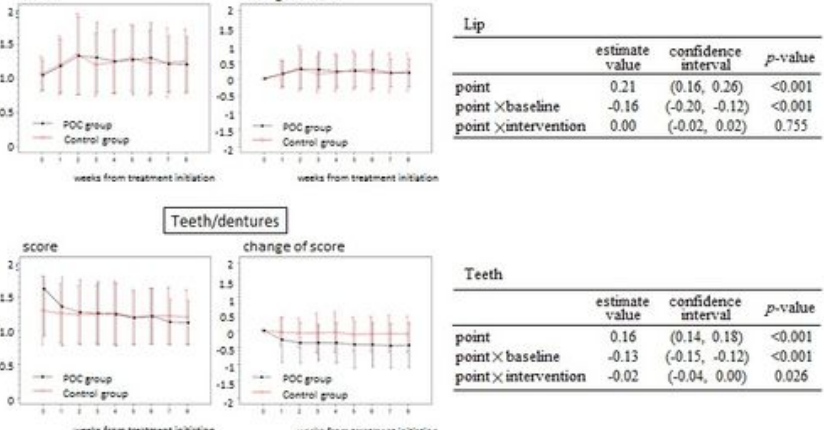

Mucous membrane
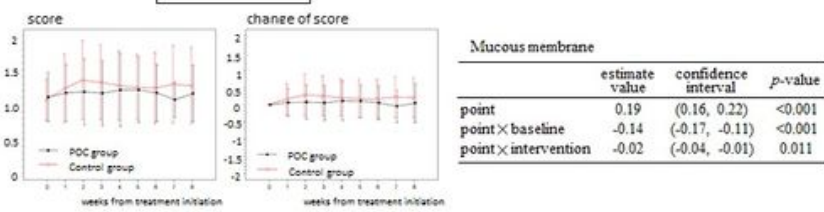

Gingivae

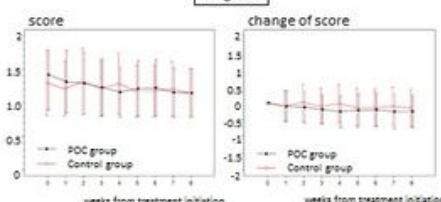

Gingivas

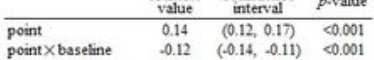
\begin{tabular}{lrrr} 
point X baseline & -0.12 & $(-0.14,-0.11)$ & $<0.001$ \\
point $X$ intervention & -0.01 & $(-0.02,0.01)$ & 0.465 \\
\hline
\end{tabular}

Tongue

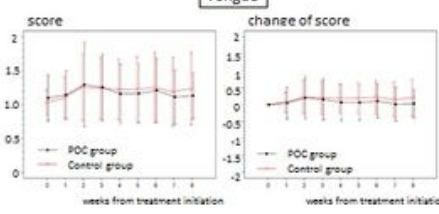

Tongue

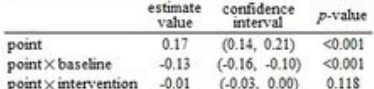
\begin{tabular}{llll} 
point $X$ baseline & -0.13 & $(-0.16,-0.10)$ & $<0.001$ \\
point $X$ intervention & -0.01 & $(-0.03,0.09)$ & 0.118 \\
\hline
\end{tabular}

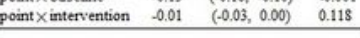

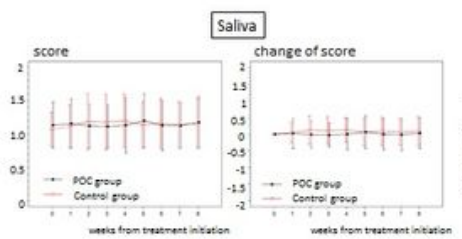

Saliva

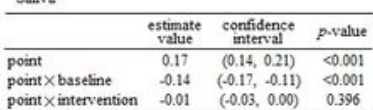

\begin{tabular}{lrrr} 
point $\times$ baseline & -0.14 & $(-0.17,-0.11)$ & $<0.001$ \\
point $\times$ intervention & -0.01 & $(-0.03,0.00)$ & 0.396 \\
\hline
\end{tabular}

mens tom trutreet intation

menes tom veratrent interton

C.

\section{Figure 3}

Longitudinal data of each OAG score in the POC group and the control group OAG, Oral Assessment Guide; POC, professional oral care

\section{Supplementary Files}


This is a list of supplementary files associated with this preprint. Click to download.

- renamedd87e5.doc 